\title{
Astaxantina: seu uso como corante natural alimentício
}

\author{
Astaxanthin: its use as natural food dye
}

RIALA6/1584

Micheli de Moraes FERREIRA ${ }^{1 *}$, Helena Pereira da Silva ZAMITH² $^{2}$, Shirley ABRANTES ${ }^{3}$

*Endereço para correspondência: ${ }^{1}$ Departamento de Tecnologia de Alimentos, Instituto de Tecnologia, Universidade Federal Rural do Rio de Janeiro, Rodovia BR 465, km 7, Seropédica, RJ, Brasil. CEP: 23.890-000. Tel: (21) 2682-1023 (ramal 206) Fax: (21) 3787-3742. E-mail: michelimedvet@yahoo.com.br

${ }^{2}$ Departamento de Farmacologia e Toxicologia, Instituto Nacional de Controle de Qualidade em Saúde, Fundação Oswaldo Cruz ${ }^{3}$ Departamento de Química, Instituto Nacional de Controle de Qualidade em Saúde, Fundação Oswaldo Cruz

Recebido: 14.07.2013 - Aceito para publicação: 06.02.2014

\section{RESUMO}

A cor e a aparência dos alimentos são os primeiros atributos fundamentais, se não os mais importantes a serem avaliados pelos consumidores no momento da sua aquisição. Os alimentos podem ser mais nutritivos, seguros e econômicos, no entanto, se não forem atraentes, sua aquisição não ocorrerá. O salmão é basicamente um peixe branco que se torna rosado pela ingestão do camarão. O pigmento vermelho armazenado presente no músculo ou na casca do camarão e que se acumula no tecido adiposo é adquirido pela ingestão das algas e dos organismos unicelulares pelos camarões do mar. Os carotenóides utilizados nas indústrias alimentícia, farmacêutica, de cosméticos e de ração são corantes naturais responsáveis pelas cores amarela, laranja e vermelha. O salmão criado em aqüicultura não tem acesso aos organismos citados acima, entretanto é adicionada à sua ração a astaxantina (ATX), substância que confere a cor rosada à sua carne. A ATX (3,3'-dihidroxi-beta,beta-caroteno-4,4'-diona) é um pigmento carotenóide oxigenado, que confere a característica de coloração rosa-avermelhada a alguns peixes, crustáceos, aves e microrganismos. A ATX apresenta potente atividade na eliminação de radicais livres e na proteção quanto à peroxidação de lipídios e quanto aos danos causados pela oxidação das membranas celulares e de tecidos.

Palavras-chave. salmão, carotenoide, alimento.

\begin{abstract}
The color and appearance of food are the first fundamental attributes, if not the most important, to be evaluated by consumers at the time of its acquisition. The food can be more nutritious, safer and more economical, however, if it is not attractive, its acquisition will not occur. Basically, salmon is a white fish that becomes pink by eating shrimp. The stored red pigment existing in the shrimp muscle or shell, which is accumulated in the adipose tissue, is acquired through the ingestion of algae and unicellular organisms by the marine shrimps. The carotenoids employed in the food, pharmaceutical, cosmetics and feed industries are natural colorants responsible for providing yellow, orange and red colors. As the salmon raised in aquaculture do not have access to the organism above mentioned, the astaxanthin (ATX), a substance that gives a pinkish color to salmon meat, is added to their feed. ATX (3,3'-dihydroxy-beta,beta-carotene-4, 4 '-dione) is a oxygenated carotenoid pigment which confers the characteristic reddish-pink coloration to certain fish, crustaceans, birds and microorganisms. The ATX has potent activity in removing the free radicals and protecting against the lipid peroxidation and the damage caused by oxidation of cell and tissues membranes.
\end{abstract}

Keywords. salmon, carotenoids, food. 


\section{INTRODUÇÃO}

A cor é a primeira informação que temos de um alimento. A partir da cor bem como da textura podemos classificar qualquer alimento inicialmente, por exemplo, em agradável/aceitável ou mesmo repugnante. Geralmente são fatores facilmente perceptíveis e avaliados pelos consumidores, que podem ser altamente nutritivos e conferir ganhos a saúde. A aceitação do alimento está, pois, diretamente e principalmente relacionada à sua aparência.

A aparência de um alimento também pode contribuir de forma inversa quanto à avaliação pelo consumidor, pois, um alimento com poucos nutrientes pode ter sua apresentação melhorada para que seja mais requisitada, pelo menos em um primeiro instante. A cor acompanhada pela primeira impressão da textura faz parte do apelo comercial do produto.

Os carotenóides são corantes naturais responsáveis pelas cores amarela, laranja e vermelha, utilizados nas indústrias alimentícia, farmacêutica, de cosméticos e ração. A produção biotecnológica de carotenóides vem se destacando devido a fatores tais como possibilidade de utilização de substratos de baixo custo para a bioprodução; denominação de substâncias naturais; pequeno espaço para produção e, controle das condições de cultivo. Muitos micro-organismos produzem carotenóides, porém nem todos são industrialmente interessantes ${ }^{1}$. Em animais aquáticos, possui muitas funções, tais como proteção de ácidos graxos poliinsaturados contra oxidação, proteção contra radiação ultravioleta, entre outros ${ }^{2}$.

A astaxantina (3,3'-dihidroxi-beta,betacaroteno-4,4'-diona) é um pigmento carotenóide oxigenado, que confere a característica de coloração rosa-avermelhada de alguns peixes, crustáceos, aves e micro-organismos, apresentando forte atividade de eliminar radicais livres e proteger contra peroxidação de lipídios e danos causados pela oxidação das membranas celulares e tecidos. Como os carotenóides não são sintetizados pelos animais, atualmente é crescente o seu uso como alimento funcional e suplemento farmacêutico. Sua adição é utilizada como suplemento alimentar nas dietas de peixes e crustáceos em aquicultura, fornecendo característica de pigmentação destes animais, e na criação de aves domésticas visa aumentar a cor da gema do ovo, incrementando sua qualidade e aceitação no mercado consumidor ${ }^{3}$.
Sendo assim este estudo visa abordar as diferentes formas de emprego da astaxantina (ATX) na produção de alimentos.

\section{Estrutura Química e Propriedades Biológicas da ATX}

A ATX (Figura 1) é um pigmento encontrado em animais aquáticos, tais como lagosta, siri e camarão. Este pigmento protege contra radicais livres, peroxidação lipídica, danos oxidativos ao colesterol lipoproteico de baixa densidade, oxidação dos ácidos graxos poliinsaturados essenciais e proteção contra os efeitos da luz ultravioleta (UV) nas membranas celulares e tecidos ${ }^{4}$.

Devido à alta taxa de insaturação, fatores tais como calor, luz e ácidos ocasionam isomerização dos carotenóides trans, que é a forma mais estável na natureza, para a forma cis (Figura 2) promovendo ligeira perda de cor e atividade pró-vitamínica. Os carotenóides são também susceptíveis às oxidações enzimáticas ou não enzimáticas, que dependem da estrutura do carotenóide, disponibilidade de oxigênio, presença de enzimas, metais, pró-oxidantes e antioxidantes, alta temperatura e exposição à luz .

Os pigmentos podem absorver luz especificamente UV e visível do espectro, o restante é transmitido ou refletido, e apresentam cor. A estrutura responsável pela absorção da luz é o grupamento cromóforo, que nos carotenóides se caracteriza pelas duplas ligações conjugadas. Cada carotenóide é caracterizado por um espectro de absorção eletrônica. Assim, a espectroscopia de absorção é uma importante técnica na análise de carotenóides ${ }^{6}$.

A maioria dos carotenóides são tetraterpenoides com quarenta carbonos (C40) e 8 unidades isoprenoides, ligados de tal forma que a molécula é linear e simétrica, com a ordem invertida no centro. A estrutura básica acíclica C40 pode ser modificada por hidrogenação, desidrogenação, ciclização ou oxidação. A característica de absorção de luz destes pigmentos dá-se devido à cadeia de duplas ligações conjugadas que atua como cromóforo, sendo necessário, aproximadamente, sete ligações duplas conjugadas para que o carotenóide apresente coloração. O sistema de duplas ligações conjugadas também confere a estes pigmentos alta reatividade química, podendo ser facilmente isomerizados e oxidados, principalmente quando submetidos a condições não controladas de processamento e/ou estocagem, mais especificamente em produtos naturais (frutas). Além disso, o calor, a luz, o oxigênio e enzimas como lipoxigenase e/ou 
ácidos presentes em frutas levam a alterações ou parcial destruição dos pigmentos. A exposição destes pigmentos a tais agentes resulta na formação de isômeros cis, epóxidos, diminuição da cor, perda da atividade próvitamínica A e quebra da cadeia ${ }^{1}$.



Figura 1. Estrutura da ATXtrans



Figura 2. Estrutura da ATX cis

Após ingestão, devido a sua liposolubilidade, a ATX é incorporada em micelas no intestino delgado, se difundindo passivamente na luz intestinal junto com os ácidos graxos. A ATX é incorporada em quilomícrons e estes apos perderem sua fração lipídica, tornamse suficientemente pequenos para passar através dos capilares sanguíneos, chegando ao fígado, principal órgão para metabolismo e excreção de carotenóides. Neste órgão, a ATX é catabolizada até seus metabólitos. O mecanismo exato pelo qual a ATX é metabolizada no fígado é desconhecido, mas a porção deste carotenóide não metabolizada é incorporada as lipoproteínas de muito baixa densidade antes de chegar a corrente sanguínea novamente ${ }^{7}$.

Apesar da ausência da atividade pró-vitamina A, a ATX possui inúmeras propriedades farmacológicas incluindo atividades antioxidante, antiinflamatória ${ }^{8}$, imunomoduladora, anticâncer ${ }^{9} \mathrm{e}$ antidiabetes ${ }^{10}$. Entre tais propriedades, sua atividade antioxidante parece ser responsável pelas demais. A ATX apresentou potencial antioxidante superior a outros carotenóides como zeaxantina, luteína, cantaxantina, e $\beta$-caroteno e 100 vezes maior que o $\alpha$-tocoferol ${ }^{11}$. Essa superioridade estaria relacionada à estrutura química, onde os anéis polares da ATX removeriam espécies reativas de oxigênio na superfície, enquanto a cadeia carbonada agiria no interior da membrana ${ }^{12}$. No anel polar da ATX, o grupo hidroxila no átomo de carbono três é apontado como principal sítio de remoção de radicais livres.

Alguns autores têm descrito o efeito protetor da ATX contra danos oxidativos induzidos por radicais hidroxilas e oxigênio singlete ${ }^{13}$. Além disso, tem sido demonstrado que peróxido de hidrogênio, oxigênio singlete e radical superóxido estimulam a biossíntese da ATX em fungos, provavelmente como uma resposta de defesa antioxidante ${ }^{14,15,16}$.

\section{Fontes da ATX e seu emprego na indústria}

A ATX é o principal pigmento carotenóide encontrado em animais aquáticos. Ele tem sido utilizado como uma fonte de pigmentação para peixes marinhos na aquicultura e também está sendo investigado para alimentos, cosméticos e aplicação médica, devido à sua alta atividade antioxidante. Os micro-organismos, alga do gênero Haematococcus, a levedura vermelha Phaffia rhodozyma, e o invertebrado Euphausia superba (krill), etc, são fontes de ATX. ATX sintética (Figura 2) é produzida por algumas empresas por meio de complexas reações químicas e seu mercado foi estimado em 100 milhões de dólares por ano no início dos anos 90. No entanto, não é, na mesma forma como encontrada na natureza, e sua estabilidade e atividade são mais baixas do que o produto natural.A astaxantina foi primeira isolada e identificada a partir de lagostas, em 1938, e muitos estudos foram realizados para extrair astaxantinaa partir de várias fontes, por solventes orgânicos ${ }^{17}$.

A deposição de ATX em trutas e salmões é muito mais eficiente, comparativamente a outros carotenóides, sendo que a maioria dos criadores utiliza ATX sintética. Contudo, o custo deste insumo é elevado, aliado ao fato de que suas formulações podem conter configurações químicas indesejadas de ATX e seus derivados, diminuindo sua eficiência na pigmentação ${ }^{18,19}$. Adicionalmente, observa-se uma tendência mundial à utilização de fontes naturais de nutrientes e à exclusão de componentes sintéticos da cadeia alimentar. Tais fatores têm aumentado o interesse em fontes naturais de ATX, sendo que diversas empresas têm investido na obtenção deste pigmento, a partir de fontes naturais ${ }^{20}$. Atualmente, as fontes naturais mais promissoras de ATX são a microalga Haematococcus pluvialis ${ }^{21}$ e a levedura Phaffia rhodozyma ${ }^{22}$. Neste contexto, a necessidade de obtenção de ATX a partir de fontes naturais com elevada 
produtividade, sustentabilidade e baixo custo, aliado ao uso de processos eficientes de extração e quantificação daquele carotenóide, vem direcionando pesquisas nesta área, buscando incrementos de qualidade e redução do custo do pescado produzido em cativeiro.

A aplicação mais comum tem sido na aquicultura, para a alimentação direta ou indireta de algumas espécies de peixes, moluscos, crustáceos e de diversos organismos forrageiros de interesse econômico. São empregadas espécies da família Bacillariophyceae (Chaetoceros spp. Ehrenberg, Thalassiosira spp. Cleve, Phaeodactylum tricornutum Bohlin e Skeletonemacostatum Greville), da família Haptophyceae (Isochrysis spp. Parke), Cryptophyceae (Rhodomonas spp. Karsten), Chrysophyceae (Monochrysis spp. Skuja), Prasinophyceae (Tetraselmis spp. Stein), Cyanophyceae (Arthrospira spp. e Spirulina spp.) e Chlorophyceae (Chlorella spp, Dunaliella spp. e Scenedesmus spp. Bourrely), dentre outras classes e diversas espécies ${ }^{23}$.

\section{Emprego da ATX na indústria de alimentos}

Com a intenção de solucionar este problema, várias pesquisas têm sido conduzidas com o objetivo de buscar fontes alternativas de pigmentos carotenóides a serem adicionadas à ração de galinhas poedeiras para melhorar a coloração das gemas e a ração de peixes para conferir cor à musculatura do pescado. Devido à tendência atual para o uso de produtos naturais, muitas algas, leveduras, vegetais e micro-organismos estão sendo estudados e recomendados para utilização como suplemento pigmentante $e^{21,24-28}$.

A retenção de carotenóides em animais depende da eficiência de absorção do transporte do aparelho digestivo, dos mecanismos de deposição em diversos tecidos, do metabolismo e da taxa de excreção. Taxas de retenção na dieta de carotenóides em salmonídeos variam de acordo com fatores tais como: sexo, tamanho, espécie e composição da dieta, mas estão geralmente na faixa de 1-18\%. Os níveis de carotenóides em salmonídeos cultivados apresentam grandes variações entre indivíduos da mesma espécie, e os valores reportados para salmonídeos selvagens podem representar as diferenças comparativas na capacidade de depositar carotenóides. Fatores que podem também contribuir para a observação são as diferentes fontes de pigmento na dieta, o tamanho do peixe, as diferentes fases de maturação e genética ${ }^{29}$.

\section{ATX e a Aquicultura}

No Brasil, a aplicação de corantes diretamente na carne do pescado é proibida, inclusive pelo Codex Alimentarius. Entretanto conforme a Resolução no 1 , de 7 de março de 2008 do Ministério da Agricultura Pecuária e Abastecimento, o seu uso na ração para promoção de cor na musculatura, é permitido. Como não dispomos de leis brasileiras sobre o assunto, nos baseamos em legislações internacionais em relação à segurança alimentar. Os limites que impomos a outros países quando da exportação de pescado colorido artificialmente por ração segue, principalmente, a União Europeia. O Art. $1^{\circ}$ da resolução tem a seguinte redação:
Adotar a expressão "Peixe de cultivo: coloração resultante do corante utilizado na ração" em todos os rótulos aplicáveis aos produtos que contenham peixes provenientes da aqüicultura cuja coloração da musculatura tenha sido obtida por meio da alimentação com rações adicionadas de corantes.

O salmão, que é um grande peixe da família Salmonidae, é peculiar aos mares e rios europeus, sendo muito procurado pela sua apreciadíssima carne rosada, muito saborosa, e criado em aquicultura, especialmente a espécie Salmo salar. O salmão do oceano Atlântico volta do mar à água doce para se reproduzir, quase sempre ao mesmo rio em que nasceu. À medida que se aproxima a época da procriação, a cabeça do macho muda de forma, alongando e curvando a mandíbula inferior em forma de gancho e a carne ganha uma coloração esbranquiçada. Enquanto o salmão do oceano Pacífico morre após a reprodução, o do Atlântico se reproduz mais de uma vez.

O salmão é basicamente um peixe branco. O pigmento vermelho é adquirido através das algas e dos organismos unicelulares, que são ingeridos pelos camarões do mar; o pigmento é armazenado no músculo do camarão ou na casca. Quando os camarões são ingeridos pelo salmão, estes também acumulam o pigmento nos seus tecidos adiposos. Como a dieta do salmão é muito variada, o salmão natural apresenta uma enorme variedade de cores, desde branco ou cor-de-rosa suave a vermelho vivo. Permanece na água doce nos dois ou três primeiros anos de vida antes de ir para o mar. Suporta temperaturas baixas em água doce ou salgada. O salmão adulto é alimento de focas, ursos, tubarões, 
baleias e seres humanos.

O Chile é o segundo produtor mundial desse pescado. Através dos anos, sua indústria se desenvolveu e hoje é responsável por um abastecimento mundial considerável. Destaca-se a importância da "Fundación Chile", instituição de capital pública-privada voltada para assistência técnica a alguns projetos, tendo como principais funções verificar a necessidade da incorporação de novas tecnologias ${ }^{30}$. Como qualquer empreendimento de capital de risco, esta Fundação registrou muitos fracassos, mas também muitos casos de sucesso, como o cultivo de salmões ${ }^{31}$. A partir de um projeto piloto de 1981 para o cultivo de salmões em jaulas, em água doce (tecnologia desenvolvida na Noruega e Suécia), houve a primeira produção comercial em 1986-1987, duplicando no período seguinte. No ano de 1988 o ciclo se completou, quando o projeto começou a gerar lucros e a Fundação vendeu o projeto a uma companhia japonesa de pescados e mariscos comestíveis. Nos anos 1990, a exportação de salmão se tornou uma das mais importantes ${ }^{32}$.

O Chile exportou para o Brasil US\$ 192 milhões, em 2009, sendo que $81 \%$ desse valor, num total de US\$ 156 milhões, foram da categoria salmão. Em volume, o produto também representou $81 \%$ do total importado pelo país, com 36 mil toneladas de um total de $44 \mathrm{mil}$ toneladas importadas pelo país. Nota-se que quase 100 $\%$ dos salmões importados têm sua origem no Chile (Tabela 1).

É interessante observar que houve um direcionamento das vendas de salmão e trutas para o mercado brasileiro quando ocorreu a crise internacional a partir de 2008. Segundo dados do Banco Central do Chile, o país exportou estes dois produtos para o mundo num total de US\$ 2.327.500.000 em 2008. Em 2009, houve um recuo para US\$2.029.400.000, representando um decréscimo de 13\%. Paralelamente, o Brasil passou a importar mais deste país, chegando a $21 \%$. Ou seja, a participação relativa brasileira nas compras do Chile foi aumentada em plena crise econômica internacional. Sem desconsiderar que houve um aumento de $10 \%$ no preço médio do pescado importado do Chile entre 2008 e 2009. Portanto, devido à estabilidade econômica brasileira, ao crescimento da renda média nacional e ao esforço exportador das empresas chilenas, o país apresentou um comportamento destoante dos demais compradores mundiais.

O consumo nacional de salmão em quilogramas teve aumento total de $16 \%$ em relação a 2008. Neste período apenas os salmões congelados, cuja participação relativa é a segunda em importância, tiveram suas compras aumentadas em $76 \%$. Os salmões frescos, maior item da categoria, apresentaram redução de $2 \%$ na comparação com 2008. Os salmões defumados tiveram uma queda de $4 \%$ entre 2008 e 2009 (Tabela 1).

Nota-se que os salmões congelados tiveram aumento no volume e valor importados. Houve pequeno aumento de preço em comparação ao ano anterior, $7 \%{ }^{33}$.

O Chile foi o principal fornecedor de pescado para o mercado brasileiro com 261 milhões de dólares em 2010. De acordo com dados do governo chileno, o Brasil foi o terceiro destino das exportações chilenas de pescado com US\$ 247 milhões, cerca de $12 \%$ do total exportado em valores monetários ${ }^{34}$.

O salmão cultivado segue como o segundo produto mais importado, sendo o Chile seu maior fornecedor, que exporta também grandes quantidades de truta para o mercado brasileiro, além de outros pescados.

Porém como o habitat natural do salmão são as águas europeias onde está presente sua alimentação em abundância, em uma criação em cativeiro, é preciso

Tabela 1. Importações brasileiras de salmões nos anos 2008 e 2009

\begin{tabular}{|c|c|c|c|c|c|c|c|c|c|}
\hline Produtos & \multicolumn{3}{|c|}{2008} & & & \multicolumn{4}{|c|}{2009} \\
\hline Salmões frescos & 24.0052 .436 & $104.429 .634,00$ & 4,34 & 23.513 .358 & $121.917 .644,00$ & 5,19 & $-2 \%$ & $17 \%$ & $19 \%$ \\
\hline Salmões congelados & 7.137 .611 & $17.758 .566,00$ & 2,49 & 12.577 .251 & $33.507 .209,00$ & 2,66 & $76 \%$ & $89 \%$ & $7 \%$ \\
\hline Salmões defumados & 74.068 & $898.029,00$ & 12,12 & 71.283 & $861.349,00$ & 12,08 & $-4 \%$ & $-4 \%$ & - \\
\hline Total & 31.264 .115 & $123.068 .229,00$ & 3,94 & 36.161 .892 & $156.286 .202,00$ & 4,32 & $16 \%$ & 27 & $10 \%$ \\
\hline
\end{tabular}

Fonte: Ministério da Pesca e Aquicultura - Boletim estatístico da pesca e aquicultura, 2008-2009 
que se adicione um complemento à alimentação desse pescado, sendo assim uma alternativa usada para se chegar a uma coloração típica da carne é o uso da ATX, que já está presente de forma natural na alimentação dos peixes europeus.

No cultivo de peixes como a tilápia vermelha e de crustáceos, a ATX é comumente adicionada à ração animal para compensar a falta da ocorrência natural deste pigmento. Além de promover a pigmentação, o crescimento e a sobrevivência dos animais cultivados, este pigmento também estimula o sistema imunológico de trutas. No entanto, o estímulo não é suficiente para que a ATX seja incluída como um agente imuno-estimulante nas formulações alimentares ${ }^{27}$.

Os ovos de galinha são uma rica fonte de nutrientes vitais e, por isso, são comumente usados na alimentação humana. O grau de pigmentação das gemas de ovos depende basicamente do desejo do consumidor e varia com a área geográfica, tradição e cultura.

\section{ATX e avicultura}

Em muitas áreas de mercado ao redor do mundo, consumidores e indústrias que produzem alimentos contendo ovos em sua formulação (maionese, misturas para bolos, produtos de confeitaria, massas, e outros) preferem gemas de ovos fortemente coloridas, sendo difícil resistir ou ignorar essa tendência cultural e comercial ${ }^{24,25,34-36}$. Em geral, o uso de rações ricas em carotenóides, ou de suplementos carotenóides na ração, efetivamente, mantém ou aumenta a coloração. Estas práticas têm se tornado o principal meio de conseguir a coloração desejada em vários produtos de origem animal, incluindo gemas de ovos ${ }^{37}$.

Akiba et $\mathrm{al}^{24}$ avaliaram o potencial pigmentante da gema de ovos com Phaffia rhodozyma, uma levedura contendo altos teores de oxicarotenóides em comparação com a páprica, uma fonte pigmentante de ocorrência natural, e os resultados mostraram que a levedura pode ser uma fonte útil para o propósito almejado.

ATX natural derivada de Haematococcus tem sido usado com sucesso como pigmento para gemas de ovos. Galinhas White Leghorn foram alimentadas com uma dieta basal durante duas semanas para esgotar seus níveis de carotenóides; no momento do início do experimento, obtendo ovos com uma média de pontuação de 4 cores no indicador ou tabela de cores Roche. Novas dietas foram preparadas e suplementadas com 0,$5 ; 1,0 ; 1,5$; 2,0 e 3,0 mg. $\mathrm{kg}^{-1}$ de ATX a partir de homogeneizado de
Haematococcus, que foram fornecidas aos animais por um período de quatro semanas. Após cerca de sete dias, os pigmentos de gema de ovo atingiram pontuações estáveis de 5,$8 ; 7,9 ; 9,4 ; 10,1$ e 11,8 na escala de cores, obtidas de galinhas alimentadas com rações suplementadas com 0,$5 ; 1,0 ; 1,5 ; 2,0$ e 3,0 mg. $\mathrm{kg}^{-1}$ de ATX, respectivamente. As pontuações de cor foram correlacionadas com um aumento de concentrações de ATX, zeaxantina e luteína nas gemas ${ }^{38}$.

Trans-ATX foi detectada nos músculos $(0,1$ a 0,3 $\left.\mu \mathrm{g} . \mathrm{g}^{-1}\right)$ e fígado $\left(0,3-1,1 \mathrm{mg} \cdot \mathrm{g}^{-1}\right)$ de frangos alimentados com levedura, Phaffia rhodozyma, mas não em frangos de controle, a concentração de trans-ATX subiu parcialmente na proporção da concentração da ATX na dieta. O valor da cor da carne do peito foi intensificada com o aumento da ATX na dieta, embora este resultado não fosse estatisticamente significativo. Enquanto a ATX seja parcialmente metabolizada para idoxantina e crustaxantina, no fígado de galinha, é provável que a pigmentação da carne seja principalmente devido a ATX, que é diretamente incorporada na carne. A função biológica de carotenóides tem recebido uma atenção significativa nos últimos anos. A ATX mostra uma maior atividade antioxidante e propriedades imunomoduladoras em tecidos animais. ATX depositada $(0,1$ a1,1 $\left.\mu \mathrm{g} . \mathrm{g}^{-1}\right)$ em tecidos pode ser de interesse em termos da prevenção da peroxidação do tecido em carne de galinha e, desse modo, poderia ser uma fonte de alimentação para consumo humano, que também tenha uma função adicional biológicaa ${ }^{24}$.

Há uma quantidade crescente de evidências que sugerem que a ATX supera os benefícios antioxidantes do $\beta$-caroteno, zeaxantina, cantaxantina, vitamina $\mathrm{C}$ e vitamina E. Também têm demonstrado que a ATX pode proteger a pele dos efeitos nocivos da radiação ultravioleta, relacionada com a idade e degeneração macular, proteger contra cânceres induzidos quimicamente, aumentar lipoproteínas de alta densidade e melhorar o sistema imunitário. Estudos epidemiológicos têm demonstrado uma correlação entre $\mathrm{o}$ aumento de ingestão de carotenóides e redução da incidência de doença cardíaca coronária e certos tipos de câncer, degeneração macular e aumento de resistência a infecções virais, bacterianas, fúngicas e parasitárias. Estudos indicam que o mecanismo para esta proteção é um atributo, em parte, devido ao aumento direto da resposta imune pelos carotenóides. Efeitos anticarcinogênicos dos carotenóides são susceptíveis de serem atribuíveis ao seu 
efeito antioxidante, de modo como os radicais livres de oxigênio estão relacionados com o processo de iniciação e propagação de câncer ${ }^{38}$.

\section{CONCLUSÃO}

A ATX é um carotenóide que oferece grande utilização na indústria de alimentos, sendo usada inicialmente em criações de animais como aditivo a ração, como no caso da aqüicultura do salmão e na avicultura de ovos.

A extração da ATX em meio in natura se torna inviável em razão dos custos elevados, porém a obtenção de uma ATX, através da produção e extração de algas, mostrou ser uma alternativa mais econômica e eficiente para a obtenção deste corante.

\section{REFERÊNCIAS}

1. Valduga E, Tastsch PO, Tiggemann L, Treichel H, Toniazzo G, Zeni J. Produção de carotenóides: microrganismos como fonte de pigmentos naturais. Quim Nova.2009;32(9):2429-36.

2. Higuera-Ciapara I, Félix-Valenzuela L, Goycoolea FM. Astaxanthin: a review of its chemistry and applications. Crit Rev Food Sci Nutr. 2006;46(2):185-96.

3. Fonseca RAS, Burkert JFM, Kalil SJ, Burkert CAV. Seleção de linhagem de Phaffia rhodozyma para produção de astaxantina. In: XXI Congresso de Iniciação Científica e Tecnológica em Engenharia, VI Feira de Protótipos. CRICTE: Rio Grande do Sul; 2006.

4. Hu ZC, Zheng YG, Wang Z, Shen YC. pH control strategy in astaxanthin fermentation bioprocess by Xanthophyllomyces dendrorhous. Enz Microb Technol.2006;84:164-6.

5. Johnson EA, Schroeder WA. Singlet oxygen and peroxyl radicals regulate carotenoid biosynthesis in Phaffia rhodozyma. J Biol Chem.1995;270(31):18374-9.

6. Gross J. Pigments in vegetables: chlorophylls and carotenoids. New York: Van Nostrand Reinhold; 1991.

7. Rajasingh H, Oyehaug L, Vage DI, Omholt SW. Carotenoid dynamics in Atlantic salmon. BMC Biol.2006;4:1-15.

8. Kurashige M, Okimasu E, Inoue M, Utsumi K. Inhibition of oxidative injury of biological membranes by astaxanthin. Physiol Chem Phys Med NMR.1990; 22(1):27-38.

9. Chew BP, Park JS, Wong MW, Wong TS. A comparison of the anticancer actitives of dietary beta carotene, canthaxanthin and astaxanthin in mice vivo. Anticancer Res.1999;19(3A):1849-53.

10. Uchiyama K, Naito Y, Hasegawa G, Nakamura N, Takahashi J, Yoshikawa T. Astaxanthin protects beta-cells against glucose toxicity in diabetic db/db mice. Redox Rep.2002;7(5):290-3.

11. Naguib YMA. Antioxidant activities of astaxanthin and related carotenoids. J Agric Food Chem.2000;48(4):1150-4.
12. Goto S, Kogure K, Abe K, Kimata Y, Kitahama K, Yamashita $\mathrm{E}$, et al. Efficient radical trapping at the surface and inside the phospholipid membrane is responsible for highly potent antiperoxidative activity of the carotenoid astaxanthin. Biochim Biophys Acta.2001;1512(2):251-8.

13. Wu TH, Liao JH, Hou WC, Huang FY, Maher TJ, Hu CC. Astaxanthin protects against oxidative stress and calciuminduced porcine lens protein degradation. J Agric Food Chem.2006;54(6):2418-23.

14. Schroeder WA, Johnson EA. Antioxidant role of carotenoids in Phaffia rodhozyma. J Gen Microbiol.1993;139:907-12.

15. Schroeder WA, Johnson EA. Singlet oxygen and peroxyl radicals regulate carotenoid biosynthesis in Phaffia rhodozyma. J Biol Chem.1995;270(31):18374-9.

16. Liu YS, Wu JY. Hydrogen peroxide-induced astaxanthin biosynthesis and catalase activity in Xanthophyllomyces dendrorhous. Appl Microbiol Biotechnol.2006;73(3):663-8.

17. Lim G-B, Lee S, Lee E, Haam S, Kim W. Separation of astaxanthin from red yeast Phaffia rhodozyma by supercritical carbon dioxide extraction. Biochem Eng J.2002;11:181-7.

18. Latscha T. Carotenoids: their nature and significance in animal feeds. Basel: Hoffman-La Roch; 1990. 110 p.

19. Torrissen OJ, Christiansen R. Requirements for carotenoids in fish diets. J Appl Ichthyol.1995;11(3-4):225-30.

20. Mccoy M. Astaxanthin market a hard one to crack. Chem Eng News.1999;77(14):15-7.

21. Gouveia L, Gomes E, Empis J. Potential use of microalgae (Chlorella vulgaris) in the pigmentation of rainbow trout (Oncorhynchusmykiss) muscle. Z Lebensm Unters Forsch.1996;202:75-9.

22. Moriel DG, Chociai MB, Machado IMP, Fontana JD, Bonfim TMB. Effect of feeding methods on the astaxanthin production by Phaffia rhodozyma in fed-batch process. Braz Arch Biol Technol.2005;48(3):397-401.

23. Muller-Feuga A. Microalgae for aquaculture. In: Richmond A, editor. Handbook of microalgal culture: biotechnology and applied phycology. Oxford: Blackwell Science; 2004. p.352-64.

24. Akiba Y, Sato K, Takahashi K, Matsushita K, Komiyama H, Tsunekawa $\mathrm{H}$, et al. Meat color modification in broiler chickens by feeding yeast Phaffia rhodozyma containing high concentrations of astaxanthin. J Appl Poult Res.2001;10:154-61.

25. El Boushy AR, Raterink R. Egg yolk pigmentation. World Rev Anim Prod.1992;27(1):49-62.

26. Ogawa M, Maia EL, Fernandes AC, Nunes ML, Oliveira MEB, Freitas ST. Waste from the processing of farmed shrimp: a source of carotenoid pigments. Ciênc Tecnol Aliment.2007;27(2):333-7.

27. Ponsano EHG, Pinto MF, Garcia Neto M, Lacava PM. Evaluation of Rhodocyclus gelatinosus biomass for broiler pigmentation. J Appl Poult Res.2002;11(1):77-82.

28. Tolasa S, Cakli S, Ostermeyer, U. Determination of astaxanthin and canthaxanthin in salmonid. Eur Food Res Technol.2005;221:787-91.

29. Ffrench-Davis R. Debty-Equity swaps in Chile. In: Economic reforms in Chile: from dictatorship to democracy. Michigan, EUA: Michigan Press; 2002. 263 p. 
30. Agosin M. Comercio y crecimiento en Chile. Rev CEPAL.1999;68:79-100.

31. CEPAL. América Latina y el Caribe: políticas para mejorar la inserción en la economia mundial. Santiago de Chile: Fondo de Cultura Económica; 1998.

32. Brasil. Ministério da Pesca e Aquicultura. Boletim estatístico da pesca e aquicultura: Brasil 2008-2009. Brasília: MPA; 2010. 99 p.

33. Brasil. Ministério da Pesca e Aquicultura. Boletim estatístico da pesca e aquicultura: Brasil 2010. Brasília: MPA; 2012.

34. Bauernfeind JC. Carotenoid vitamin A precursors and analogs in food and feeds. J Agric Food Chem.1972;20(3):456-73.
35. Marusich WL, Bauernfeind JC. Oxycarotenoids in poultry feeds. In: Bauernfeind JC, editor. Carotenoids as colorants and vitamin A precursors. New York: Academic Press; 1981. p. 319-462.

36. Williams WD. Origin and impact of color on consumer preference for food. Poultry Sci.1992;71(4):744-6.

37. Hudon J. Biotechnological applications of research on animal pigmentation. Biotechnol Adv. 1994;12(1):49-69.

38. Lorenz RT, Cysewski GR. Commercial potential for Haematococcus microalgae as a natural source of astaxanthin. Trends Biotechnol.2000;18(4):160-7. 